\title{
Condições de trabalho e clima de segurança dos operários da construção de edificações ${ }^{1}$
}

Working conditions and safety climate of construction workers Las condiciones de trabajo y el clima de seguridad entre los trabajadores de la construcción de edificios

\author{
Maria Cristina SILVA ${ }^{2}$ \\ Livia de Oliveira BORGES \\ Universidade Federal de Minas Gerais, Belo Horizonte, MG, Brasil
}

ResumO Este artigo explorou como operários percebem as condições de trabalho e o clima de segurança na organização em que trabalham e quais são as relações entre as percepções dos dois fenômenos. Foi aplicado um questionário sobre condições de trabalho e outro sobre clima de segurança. Participaram 195 operários de uma construtora e incorporadora da construção de edificações de Belo Horizonte. Foram realizadas análises estatísticas das respostas aos questionários. Os resultados indicaram que os participantes percebem o trabalho como repetitivo, com situações desgastantes e expostos a mudanças físicas naturais. Sentem-se exigidos em sua qualificação profissional e valorizam o trabalho em equipe e com flexibilidade para a definição de suas atividades. A análise de cluster identificou perfis de clima de segurança e ausência de clima consolidado de segurança. Aplicando a ANOVA, verificou-se que os fatores Movimentos repetitivos, Trabalho em equipe, Falta de apoio na execução das tarefas e Discriminação social e sexual influenciam significativamente os perfis de clima de segurança. Conclui-se que a percepção das condições de trabalho pode afetar a percepção do clima de segurança.

Palavras-chave:

Condições de trabalho; clima de segurança; segurança do trabalho.

Abstract This article explored how workers perceive their working conditions and aspects of the safety climate in their organization, and what the relations are between the perceptions of the two phenomena.

We applied one questionnaire about working conditions and another about safety climate. The participants were 195 workers from a contracting company in Belo Horizonte. Statistical analyses were conducted on participant responses. The results showed that they perceive the work as repetitive, leading to stressful situations and exposure to natural physical changes. They are challenged in their professional capacities, and value teamwork and flexibility in defining their activities. Cluster analysis identified safety climate profiles and the absence of a consolidated safety climate. Using ANOVA we found that the factors Repetitive movements, Teamwork, Lack of job performance support, and Social and gender discrimination significantly influence the safety climate profiles. We concluded that the perception of working conditions can affect the perception of safety climate.

Keywords:

Working conditions; safety climate; occupational safety.

Resumen El artículo abordó cómo perciben los operarios sus condiciones de trabajo y el clima de seguridad en la organización en que trabajan y cuáles son las relaciones entre las percepciones de esos dos fenómenos. Aplicamos un cuestionario sobre las condiciones de trabajo y otro sobre el clima de seguridad. Participaron 195 operarios de una empresa de construcción civil de Belo Horizonte. Realizamos análisis estadísticos de las respuestas a los cuestionarios. Los resultados indicaron que los participantes perciben que el trabajo es repetitivo, que provoca estrés y que los expone a cambios físicos naturales. Sienten que se les exige una cuali-

1 Esta pesquisa correspondeu à dissertação desenvolvida pela primeira autora para obtenção do título de mestre no Programa de Pósgraduação em Psicologia da UFMG inserido em um projeto de pesquisa mais amplo sobre condições de trabalho da segunda autora. Registramos também que o último projeto contou com o apoio do CNPq.

2 Endereço para correspondência: Rua Luiz Balena, 52, Apto 203, Bairro Silveira, Belo Horizonte, MG, Brasil 31140380. E-mail: mcristinadecristo@gmail.com 
ficación profesional, valoran el trabajo en equipo con apertura a la definición de sus actividades. El análisis de clúster identificó perfiles del clima de seguridad y la ausencia de un clima consolidado de seguridad. Aplicando la ANOVA, descubrimos que los factores Movimientos repetitivos, Trabajo en equipo, Falta de apoyo a la ejecución de las tareas, Discriminación social y sexual influyen significativamente sobre los perfiles de clima de seguridad. Concluimos que la percepción de las condiciones de trabajo puede afectar a la percepción del clima de seguridad. Palabras-clave:

Condiciones de trabajo; clima de seguridad; seguridad en el trabajo.

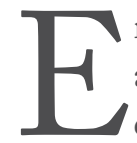

m 2012, o Produto Interno Bruto (PIB) da construção civil mostrou um crescimento de 1,4\%, superior ao do PIB brasileiro, que foi de 0,9\%. Em 2011, o setor possuía 7,8 milhões de trabalhadores empregados, 8,4\% do total de ocupados no Brasil (DIEESE, 2013), continuando a ser um setor econômico que gera emprego e renda a milhares de brasileiros. Embora apresente resultados positivos para a economia, o setor revela problemas como pouca atualização tecnológica, alta rotatividade de pessoal, pequena participação do emprego formal no total de empregados ocupados e perfil de operários com baixa instrução e experiência profissional (Costa, 2011; Costa \& Tomasi, 2014; DIEESE, 2013; Mello \& Amorim, 2009).

Segundo o DIEESE (2013), o setor de edificações no Brasil, em 2011, atingiu um índice de 125,8\% de rotatividade. No que se refere à participação no emprego, em 2011, na construção civil, apenas 30\% dos homens empregados tinham carteira de trabalho assinada; 22,3\%, não tinham e 42,4\% exerciam atividade no setor por conta própria. Dos admitidos em 2011 com carteira assinada, 58\% tinham grau de escolaridade entre analfabeto e ensino fundamental completo e incompleto. O setor é também conhecido como um dos mais perigosos para os trabalhadores em nosso país (DIEESE, 2013; Santana, Nobre, \& Waldvogel, 2005). Em 2011, a construção civil foi responsável por 8,4\% dos acidentes (MPS, 2012).

Ainda sobre o setor, em Belo Horizonte e Região Metropolitana (BHRM), no que se refere à escolaridade dos trabalhadores empregados formalmente, segundo o DIEESE (2012), 47,9\% possuíam até o ensino fundamental incompleto e apenas $47 \%$ trabalhavam com carteira de trabalho assinada. Em relação à rotatividade, o trabalhador permanecia, em média, 36 meses e recebia $92 \%$ do rendimento médio dos ocupados em outras atividades econômicas. Consideramos que esses índices sobre o setor da construção civil em BHRM assemelham-se àqueles referentes ao Brasil, anteriormente citados.

Neste cenário, a pesquisa foi planejada no segmento da construção de edificações com o objetivo de compreender a percepção das condições de trabalho e do clima de segurança na organização e as relações entre as percepções dos dois fenômenos, segundo a ótica de operários da construção de edificações.

\section{Condições de trabalho}

O trabalho não é visto somente como um valor econômico e/ou instrumental, mas também como um valor cultural e uma dimensão estruturante na vida dos indivíduos. Por isso, o estudo sobre as condições de trabalho tem sido considerado necessário para a elaboração de indicadores sociais da qualidade de vida no trabalho (Alvaro \& Garrido, 2006; Blanch, 2003). No entanto, o termo "condições de trabalho", conforme assinala Ramos, Peiró e Ripoll (2002), tem sido empregado de forma inespecífica. Segundo esses autores, tal fato pode decorrer de as condições de trabalho serem um fenômeno complexo e referido nas publicações da Psicologia do Trabalho e das Organizações (PTO) ao longo de seu desenvolvimento histórico.

As primeiras pesquisas na PTO relacionadas às condições de trabalho foram desenvolvidas nos anos de 1920 por Elton Mayo, na Western Eletric Company, e tinham como foco as questões físicas do trabalho, como os efeitos da iluminação sobre a performance dos trabalhadores (Muchinsky, 1993/1994; Zanelli, Bastos, \& Rodrigues 2014). Estudos subsequentes buscaram abordar outros aspectos, como estressores físicos, fadigas física, mental, laboral e das habilidades, acidentes de trabalho, entre outros e aspectos relacionados à vida pessoal do trabalhador (Muchinsky, 1993/1994). Mais recentemente, autores (p. ex., Prieto, 1994; Ramos et al., 2002) buscaram romper com a tendência predominante na PTO de reduzir as condições de trabalho aos aspectos ambientais, ou seja, do entorno das tarefas.

Ramos et al. (2002) assinalaram que órgãos como a Organização Internacional do Trabalho (OIT), Organização Mundial da Saúde (OMS) e Instituto Nacional de Seguridad e Higiene en el Trabajo (INSHT) têm partido da concepção de que condições de trabalho incluem os elementos que se situam em torno do trabalho e também o trabalho em si mesmo (conceito amplo). Blanch (2003), na mesma linha conceitual, 
afirmou que as condições de trabalho incidem diretamente sobre a qualidade de vida, a saúde e o bem-estar psicológico, a satisfação e a implicação com o trabalho, além de doenças ocupacionais e o rendimento. $\mathrm{O}$ autor conceitua, então, as condições de trabalho como: "Um conjunto de situações nas quais se desenvolve a atividade laboral e que influenciam significativamente, tanto a experiência do trabalho, como a dinâmica das relações laborais" (p. 43).

O conceito amplo das condições de trabalho abarca muitas categorias. Para sistematizar os estudos, autores têm elaborado taxonomias (Alvaro \& Garrido, 2006; Blanch, 2003; Muchinsky, 1993/1994; Ramos et al., 2002). Neste estudo, utilizou-se a categorização proposta por Borges, Costa, Alves-Filho e Falcão (2015), a partir da revisão de literatura dos autores citados (Tabela 1).

TABELA 1. As grandes categorias das condições de trabalho (taxonomia) e seus fatores

Categorias

\section{Conceitos}

1) Condições físicas e materiais

São os componentes mais concretos. Referem-se ao entorno das atividades de trabalho no que diz respeito às condições físicas, ao espaço geográfico, ao espaço arquitetônico e às instalações e condições de segurança física e/ou material.

Referem-se ao conjunto de aspectos que tipificam o trabalho quanto a sua natureza jurídica (autô2) Condições contratuais e jurídi- nomo versus emprego), quanto às condições contratuais no caso do emprego (formal ou informal), 2) Condições contratuais e jurídi- à estabilidade do contrato (instável ou estável) e às modalidades de contrato formal (temporário, cas por tempo indefinido). Abrange, ainda, aspectos que decorrem das condições contratuais, como o sistema de incentivo (retribuições) e as definições do tempo a ser dedicado ao trabalho.

3) Processos e características da atividade

Abrange os aspectos que dizem respeito ao conteúdo das atividades de trabalho, à organização e divisão do trabalho, às demandas do posto de trabalho, aos modos de execução das atividades e ao desempenho do trabalhador.

Diz respeito aos aspectos relacionados às interações interpessoais (sejam horizontais ou verticais), às práticas sociais relativas à gerência ou gestão quando se trata do trabalho na forma de 4) Condições do ambiente socio- emprego (pois as condições de trabalho adquirem uma dimensão organizacional) e às práticas gerencial informais, etc.).

Nota. Fonte: Borges, L. O., Costa, M. T., Alves-Filho, A., \& Falcão, J. (2015). Condições de trabalho. In P. F. Bendassolli \& J. E. Borges-Andrade (Orgs.), Dicionário brasileiro de psicologia do trabalho e das organizações (p. 230). São Paulo: Casa doPsicólogo.

\section{Clima de segurança}

O clima de segurança foi inicialmente definido por Zohar (1980) como "um resumo das principais percepções que os funcionários compartilham sobre [a segurança em] seu ambiente de trabalho” (p. 96). Uma das descobertas do autor foi a importância da participação das lideranças nos programas de segurança das empresas, indicando que esse envolvimento relaciona-se com menores índices de acidentes e programas bem-sucedidos.

Após a primeira definição de Zohar (1980), outros estudos foram desenvolvidos para melhor definir o clima de segurança e criar instrumentos de mensuração (Brown \& Holmes, 1986; Dedobbeleer \& Béland, 1991; Flin, Mearns, O'Connor, \& Bryden, 2000). Entretanto, seguiu-se sem um consenso sobre o conceito (Zohar, 2010), sendo que há autores que se centraram mais na dimensão individual do fenômeno, referindo-se às percepções ou crenças mantidas pelo indivíduo (p. ex., Dedobbeleer \& Béland, 1991), enquanto outros focaram-se na dimensão coletiva, atribuindo o clima de segurança às percepções compartilhadas por membros da organização sobre as políticas organizacionais de segurança (p. ex., Zohar, 2014). Consideradas tais divergências, optamos, nesta pesquisa, pelo conceito de Silva, Lima e Baptista (2004), que consideraram clima de segurança como as percepções compartilhadas sobre valores, normas, crenças, práticas e procedimentos em segurança.

$\mathrm{Na}$ construção civil, o primeiro estudo encontrado foi o de Dedobbeleer e Béland (1991), que obtiveram como resultado um modelo de duas dimensões: (a) comprometimento da gerência com a segurança e (b) envolvimento dos trabalhadores com a segurança. Por sua vez, Siu, Phillips e Leung (2004) - quando exploraram as relações entre clima de segurança (atitudes seguras e comunicação), questões psicológicas (sofrimento psíquico e satisfação no trabalho) e desempenho em segurança (autorrelato de acidentes e doenças ocupacionais) encontraram que: as atitudes seguras são preditoras de doenças ocupacionais; o nível de sofrimento psíquico é preditor do número de acidentes e tem relação direta e mediação sobre as taxas de acidentes; e, por fim, a comunicação não é preditora de desempenho em segurança.

Na pesquisa desenvolvida por Meliá, Mearns, Silva e Lima (2008) na construção de edificações em três países - Inglaterra, Espanha e China - os resultados encontrados sugeriram que devido a forte presença de empresas terceirizadas, os trabalhadores podem estar pouco conectados com a organização contratante e relativamente isolados da sua própria empresa; e o modo como o trabalhador e a empresa lidam com essa distância 
pode influenciar a maneira como as pessoas irão lidar com os aspectos de segurança. Silva, Araújo, Costa e Meliá (2013) encontraram diferenças no clima de segurança em canteiros de obras de uma mesma construtora.

Estudos (p. ex., Zohar \& Luria, 2010; Zohar \& Polachek, 2014) têm-se dedicado ao papel da supervisão no desenvolvimento do clima de segurança, destacando a atuação da liderança na disseminação de comportamentos seguros. No Brasil, não foram identificados estudos sobre clima de segurança na construção civil.

\section{MÉTODO}

\section{Participantes}

A pesquisa de campo foi realizada em 2012 em dois canteiros de obras de uma construtora e incorporadora de Belo Horizonte. O estudo recebeu aprovação do Comitê de Ética em Pesquisa da Universidade Federal de Minas Gerais e da empresa em que a pesquisa ocorreu. Todos os participantes preencheram um Termo de Consentimento Livre e Esclarecido antes da aplicação dos questionários.

Uma amostra acidental (ou de conveniência) foi adotada, seguindo a acessibilidade e a disponibilidade dos trabalhadores, bem como a autorização dos dirigentes dos canteiros de obras. Os questionários foram aplicados a 195 trabalhadores empregados formalmente na referida construtora. Os participantes têm em média 36,8 anos $(D P=11,96), 14,8$ meses de tempo de emprego $(D P=30,7)$, predominantemente homens $(93,3 \%)$ e de baixa instrução formal (69,8\% estudaram no máximo até o ensino fundamental completo).

\section{Instrumentos}

Para avaliar as condições de trabalho, utilizamos o Questionário de Condições de Trabalho (QCT) (Borges et al., 2013), que possui 35 questões, totalizando 153 itens, distribuídos nas quatro dimensões mencionadas anteriormente (Tabela 1). As questões referentes às Condições contratuais e jurídicas são estruturadas nominalmente. Em relação às demais dimensões, os participantes responderam às questões segundo uma escala de frequência (de nunca a sempre, ou, de 1 a 5). Referente à dimensão das Condições físicas e materiais, Borges et al. (2013) encontraram sete fatores: Falta de segurança $(\alpha=0,75)$, Exposição a situações adversas $(\alpha=0,66)$, Situações desgastantes $(\alpha=0,64)$, Movimentos repetitivos $(\alpha=0,67)$, Mudanças físicas naturais $(\alpha=0,63)$, Riscos de acidentes de trabalho $(\alpha=0,76)$ e Exposição a substâncias $(\alpha=0,69)$. Dos Processos e características da atividade, são oito fatores: Rapidez e complexidade $(\alpha=0,75)$, Interação no trabalho $(\alpha=0,74)$, Exigências de qualificação $(\alpha=0,65)$, Autonomia (jornada e escolha de colegas) ( $\alpha=0,56)$, Trabalho em equipe $(\alpha=0,54)$, Autonomia no modo de trabalho $(\alpha=0,61)$, Definição das atividades $(\alpha=0,56)$ e Responsabilidade $(\alpha=0,51)$. Finalizando, a dimensão das Condições do ambiente sociogerencial mensura cinco fatores: Falta de apoio na execução das tarefas $(\alpha=0,83)$, Discriminação social $(\alpha=0,70)$, Gestão do desempenho profissional $(\alpha=0,62)$, Discriminação sexual $(\alpha=0,63)$ e Exposição à violência $(\alpha=0,68)$.

Em referência à percepção do clima de segurança, aplicou-se o Inventário de Clima Organizacional de Segurança (ICOS) (Gonçalves, 2007), que possui 44 questões, respondidas segundo duas escalas: uma de importância, de 1 (nada importante) a 6 (muitíssimo importante); e outra de concordância, variando de 1 (discordo totalmente) a 7 (concordo totalmente). Gonçalves (2007) analisou a validade e a consistência do ICOS por meio da aplicação de análise fatorial confirmatória e estimativa do coeficiente alfa por fator. O questionário mensura quatro fatores:

1. Conteúdo do clima de segurança (CFI=0,89, RMSEA=0,11, $\alpha=0,82)$.

2. Segurança como um valor organizacional (CFI=0,89, RMSEA=0,11, $\alpha=0,74)$.

3. Práticas de segurança organizacional (CFI=0,62, RMSEA=0,10, $\alpha=0,85)$.

4. Envolvimento pessoal com segurança (CFI=0,91, RMSEA=0,09, $\alpha=0,79)$.

\section{Procedimentos}

As atividades de campo ocorreram no mês de julho de $2012 \mathrm{em}$ dois canteiros de obras em bairros distintos da cidade de Belo Horizonte, no horário de trabalho dos empregados, por equipe de estudantes sob a coordenação da primeira autora. O refeitório foi escolhido como local de aplicação, uma vez que proporcionava certa privacidade para os respondentes, contava com estrutura mínima com mesa e cadeira, além de ser um ambiente usual para os participantes. As pausas das refeições, momento em o refeitório enchia-se de trabalhadores, foram respeitadas. O tempo de aplicação dos questionários variou de acordo com a velocidade do respondente, 
uma vez que a equipe de pesquisa buscava se adaptar ao ritmo dos trabalhadores, mas duraram, em média, 30 minutos. Os questionários foram aplicados individualmente, com a leitura de perguntas e o registro das respostas em computador de mão (Pocket PC). Os dados registrados foram transferidos posteriormente para banco de dados do SPSS.

Preparando os dados para as análises dos questionários, os escores dos fatores foram estimados do QCT em três dimensões - Condições físicas e materiais, Processos e características da atividade e Condições do ambiente sociogerencial-, pela média ponderada das pontuações nos itens (respostas) pelas cargas dos mesmos itens (Borges et al., 2013). Na sequência, estimaram-se as médias em cada fator e foi aplicada a análise de variância (ANOVA) para medidas repetidas, com o objetivo de avaliar se as diferenças entre essas médias eram significativas. Por meio do teste post hoc (Bonferroni), constatou-se que os fatores das escalas contavam com níveis de frequências diferentes para os operários participantes.

Para as respostas ao ICOS, os escores nos fatores foram estimados pela média aritmética dos pontos atribuídos pelos participantes aos itens. Analisou-se, então, tais escores, por meio da ANOVA para medidas repetidas e por análise de cluster. A ANOVA permitiu comparar as médias nos fatores de clima de segurança, oferecendo um coeficiente de significância para a avaliação das diferenças. Em outras palavras, foi aplicado aos escores nos fatores de clima o mesmo raciocínio analítico aplicado aos escores de condições de trabalho por dimensões. A análise de cluster possibilitou identificar como os participantes combinam os escores atribuídos aos vários indicadores do clima de segurança. Ou seja, a técnica subdivide a amostra em subgrupos combinando seus escores, de modo a evidenciar as diferenças significativas entre eles, e, ao mesmo tempo, as semelhanças dentro do próprio grupo. Finalmente, para explorar a relação entre a percepção das condições de trabalho e do clima de segurança, os escores dos participantes nos fatores condições de trabalho segundo os clusters de clima de segurança identificados anteriormente foram comparados a partir da aplicação da ANOVA.

\section{RESULTADOS E DISCUSSÃO}

\section{Condições de trabalho contratuais e jurídicas}

Em decorrência da circunscrição das atividades de campo a uma única empresa, há homogeneidade no que se refere a todos trabalhadores serem contratados com carteira assinada para uma carga horária de 44 horas semanais, possuírem o direito a férias anuais remuneradas, um dia semanal de descanso/lazer e contribuírem à previdência social. Todos tinham também o direito à cesta básica e ao vale-transporte. Referente ao salário, $38,5 \%$ dos participantes recebiam até $\mathrm{R} \$ 900,00,44,6 \%$ de $\mathrm{R} \$ 900,00$ a $\mathrm{R} \$ 1.200,00$ e $16,8 \%$ acima de $\mathrm{R} \$$ 1.200,00. Para 52,8\% dos participantes, o salário recebido representava a única renda da família; para 20,5\%, quase a totalidade e para 14,2\%, aproximadamente a metade. A empresa possuía política de remuneração por produtividade, de forma que pagava um adicional mensalmente sobre o salário base do trabalhador. Além disso, $43,1 \%$ trabalhavam horas extras.

\section{Condições físicas e materiais}

Em referência aos fatores das Condições físicas e materiais (Tabela 2), observou-se a média mais alta no fator de Movimentos repetitivos, que é uma característica comum no setor da construção civil, já que as atividades são realizadas em etapas que seguem uma sequência repetida de ações (Costa, 2011). A observação da execução do trabalho durante o processo de coleta de dados revela, no entanto, que se trata de uma repetição distinta daquela típica do taylorismo-fordismo, à medida que não se trata de repetição apenas de movimentos ou operações, mas de tarefas. Corresponde melhor à descrição do trabalho como manufatureiro, com traços da organização do trabalho por ofícios (Costa \& Tomasi, 2014).

$\mathrm{Na}$ segunda faixa de médias (conforme a aplicação do teste post hoc), foram encontrados os fatores Situações desgastantes, Falta de segurança e Mudanças físicas naturais. No fator Situações desgastantes, a maioria dos operários se percebeu exposta em frequência moderada a exigências psíquicas estressantes, agravo de doenças contraídas, posições dolorosas ou fatigantes e à fumaça, pó ou poeiras. No fator Falta de segurança, houve mais dispersão entre as respostas dos participantes, indicando que, embora a maior concentração esteja nas respostas de menor frequência, uma porcentagem percebeu falta de segurança. O fator Mudanças físicas naturais aborda a exposição ao calor desconfortável, mudança brusca de temperatura, frio desconfortável e sol prolongado. 
Além disso, os canteiros são implantados em terrenos vazios, com poucas coberturas, e a avaliação pelos participantes provavelmente foi influenciada pelas características e limiares de frio e calor individuais.

TABELA 2. Respostas ao Questionário de Condições de Trabalho (QCT)

\begin{tabular}{|c|c|c|c|c|c|c|c|}
\hline \multirow{2}{*}{ Fatores } & \multirow{2}{*}{$M$} & \multirow{2}{*}{$D P$} & \multicolumn{4}{|c|}{$\begin{array}{l}\text { Frequência relativa de participantes } \\
\text { por intervalos }(\%)\end{array}$} & \multirow{2}{*}{ Faixa* } \\
\hline & & & $1 \leq x<2$ & $2 \leq x<3$ & $3 \leq x<4$ & $4 \leq x<5$ & \\
\hline \multicolumn{8}{|l|}{ Condições físicas e materiais } \\
\hline Movimentos repetitivos & 3,98 & 1,04 & 5,6 & 12,3 & 27,2 & 54,9 & $1^{\circ}$ \\
\hline Situações desgastantes & 2,97 & 0,92 & 15,4 & 40,0 & 29,2 & 15,4 & \\
\hline Mudanças físicas naturais & 2,95 & 0,95 & 18,5 & 36,4 & 30,3 & 14,9 & $2^{\circ}$ \\
\hline Falta de segurança & 2,84 & 1,04 & 27,2 & 30,8 & 25,6 & 16,4 & \\
\hline Riscos de acidentes de trabalho & 2,74 & 1,09 & 27,7 & 38,5 & 17,9 & 15,9 & $3^{\circ}$ \\
\hline Exposição a substâncias & 2,27 & 0,88 & 46,2 & 30,8 & 19,0 & 4,1 & $4^{\circ}$ \\
\hline Exposição a situações adversas & 1,79 & 0,66 & 65,1 & 29,2 & 5,1 & 0,5 & $5^{\circ}$ \\
\hline ANOVA (medidas repetidas) & \multicolumn{7}{|c|}{$F^{\star *}=151,46 ; p \leq 0,001(\text { Eta quadrado parcial }=0,44)^{\star \star *}$} \\
\hline \multicolumn{8}{|l|}{ Processos e características da atividade } \\
\hline Trabalho em equipe & 3,36 & 0,79 & 1,5 & 14,9 & 29,2 & 54,4 & \multirow{2}{*}{$1^{\circ}$} \\
\hline Exigências de qualificação & 3,12 & 0,86 & 4,6 & 17,9 & 37,9 & 39,5 & \\
\hline Definição das atividades & 3,03 & 0,85 & 2,6 & 27,2 & 34,9 & 35,4 & $2^{\circ}$ \\
\hline Rapidez e complexidade & 2,71 & 0,87 & 8,7 & 30,3 & 42,1 & 19,0 & $3^{\circ}$ \\
\hline Autonomia no modo de trabalho & 2,06 & 0,95 & 34,4 & 32,8 & 25,1 & 7,7 & 10 \\
\hline Autonomia (jornada e escolha de colegas) & 1,78 & 0,80 & 42,6 & 39,5 & 15,4 & 2,6 & $4^{-}$ \\
\hline Responsabilidade & 1,48 & 0,68 & 61,5 & 29,7 & 7,7 & 1,0 & $5^{\circ}$ \\
\hline Interação no trabalho & 1,37 & 0,55 & 65,6 & 31,3 & 3,1 & - & $6^{\circ}$ \\
\hline ANOVA (medidas repetidas) & \multicolumn{7}{|c|}{$F=215,96 ; p \leq 0,001$ (Eta quadrado parcial $=0,53$ ) } \\
\hline \multicolumn{8}{|l|}{ Condições do ambiente sociogerencial } \\
\hline Falta de apoio na execução das tarefas & 2,04 & 0,88 & 29,2 & 45,1 & 18,5 & 7,2 & 1 은 \\
\hline Gestão do desempenho profissional & 1,79 & 0,90 & 47,2 & 31,3 & 16,4 & 5,1 & $2^{\circ}$ \\
\hline Exposição à violência & 1,12 & 0,44 & 90,8 & 7,2 & 1,0 & 1,0 & \\
\hline Discriminação social & 1,06 & 0,23 & 94,4 & 5,6 & - & - & $3^{\circ}$ \\
\hline Discriminação sexual & 1,06 & 0,30 & 95,4 & 3,1 & 1,5 & - & \\
\hline ANOVA (medidas repetidas) & \multicolumn{7}{|c|}{$F=205,02 ; p \leq 0,001$ (Eta quadrado parcial $=0,52)$} \\
\hline
\end{tabular}

Nota. *A faixa das médias foi estabelecida com base nos resultados da aplicação do teste pos hoc Bonferroni, como parte da ANOVA para medidas repetidas; ${ }^{*}$ Considerando o coeficiente $F$ usando a correção das estimativas da esfericidade de Greenhouse e Geisser, porque o teste de Mauchly indicou a violação da hipótese de esfericidade (Condições físicas e materiais $\left(\chi^{2}(20)=146,76 ; p<0,01\right)$; Processos e características das atividades $\left(\chi^{2}(27)=172,72 ; p<0,01\right)$; e Condições do ambiente sociogerencial $\left(\chi^{2}(9)=268,49 ; p<0,01\right)$ Field $(2009)$;

${ }^{* \star \star}$ Este coeficiente descreve a proporção da variabilidade total.

Sobre o fator Riscos de acidentes de trabalho, houve uma concentração nas respostas de baixa frequência, revelando que os trabalhadores tendem a se perceber raramente ou algumas vezes expostos a riscos de acidentes, contrastando com o que foi observado nos canteiros de obras. Tais resultados podem ser a manifestação da tendência assinalada por Castillo e Cubillos (2012) de o trabalhador latino naturalizar as formas de violência vivenciadas.

Nos fatores de Exposição a substâncias e Exposição a situações adversas, os participantes apresentaram respostas centralizadas nas menores frequências, uma vez que estão relacionados, por exemplo, à percepção de baixa exposição a vapores, ao contato com produtos ou substâncias químicas, bem como à exposição a riscos de acidentes no trânsito, radiações e luz de soldadura e a trabalhar em vias públicas. Tais características faziam parte da rotina apenas de operários que usam máquinas ou instrumentos para determinadas atividades, não sendo comum à maioria dos trabalhadores da construção civil. Ao mesmo tempo, indica certa naturalização em lidar com o cimento, entre outras substâncias, que não são isentas de gerar prejuízos à saúde, mas incorporadas nas rotinas de trabalho.

\section{Processos e características da atividade}

Nesta dimensão, as médias mais elevadas foram nos fatores Trabalho em equipe e Exigências de qualificação (Tabela 2). O primeiro corresponde a uma característica presente na construção de edificações, tendo em vista o modelo de produção em etapas (conforme descrito por Costa e Tomasi (2014)), que gera interdependência entre as equipes para a finalização de uma atividade específica, bem como o modo de socialização tradicional, 
em que normalmente um servente acompanha outro profissional e com ele aprende habilidades, podendo galgar um novo cargo, como descreve Borges, Ros-García e Tamayo (2001).

Em referência ao fator Exigência de qualificação, os operários frequentemente percebem que sua atividade exige formação suplementar, qualificações e experiência. No cenário atual da construção civil, vive-se a escassez da mão de obra. Uma vez que as empresas não conseguem recrutar esses profissionais no mercado, há demanda para que os operários aprendam e sejam promovidos para ocupar determinadas funções, fazendo com que eles percebam essa exigência frequente por qualificação. Não há tempo para aprender pelos caminhos tradicionais no setor (com os companheiros e mestres). Os resultados nesse fator corroboram o que tem sido sublinhado por Mello e Amorim (2009) sobre o descompasso entre o crescimento do setor econômico e sua capacidade de atrair pessoal qualificado.

O fator Definição das atividades refere-se à escolha das tarefas pela equipe de trabalho, pelo chefe ou pelo trabalhador. No setor da construção de edificações, a hierarquia de postos é definida tradicionalmente, porém, os estilos de gestão e liderança adotados por engenheiros, mestres e encarregados podem variar. Provavelmente por isso, houve mais dispersão das respostas dos trabalhadores a esse fator que nos anteriormente comentados, apesar da magnitude de sua média posicioná-la na segunda faixa.

O fator Rapidez e complexidade demonstra o quanto o operário percebe que o trabalho implica prazos curtos e ritmo acelerado, realização de tarefas monótonas e complexas, interrupção de uma tarefa para realizar outras e resolução de problemas imprevistos. O ritmo de produção da construção civil muitas vezes é ditado pelo mercado e pelos clientes que pressionam o andamento da obra, tendo o operário que se adaptar a essa demanda. Encontramos a moda da distribuição dos escores no intervalo de 3 a 4, entretanto o teste post hoc Bonferroni indicou que a média está na terceira faixa quando a comparamos com as demais referentes a Processos e características da atividade. A hipótese explicativa é que parte da pressão é absorvida nos níveis gerenciais intermediários e/ou que há um processo de naturalização da pressão por parte dos participantes.

A respeito dos fatores que se referem à autonomia - Autonomia no modo de trabalho e Autonomia (jornada e escolha de colegas) -, os resultados indicaram que os operários tendem a se perceber com pouco poder de escolha e de sugestão dentro do canteiro de obras. Em outras palavras, tendem a crer pouco que podem modificar seus métodos de trabalho, o ritmo de realização e ordem das tarefas e a escolha dos seus colegas de trabalho. A dispersão das respostas nestes fatores está entre as mais acentuadas nos fatores da dimensão Processos e características da atividade. Provavelmente, tal dispersão reflita a variedade de estilos de gestão e liderança, além de os resultados corroborarem a conclusão de Costa e Tomasi (2014) de que as tendências de ampliar a racionalização do trabalho no setor não eliminaram por completo as perícias e as improvisações próprias do trabalhador de ofícios.

O fator Responsabilidade expressa em que medida o horário de trabalho é negociado pelo participante, se ele responde por erros técnicos e danos a equipamentos, máquinas e objetos. Uma vez que estes são definidos por seus superiores, a maioria dos operários não se percebeu responsável. As respostas referentes ao fator Interação no trabalho remeteram à percepção dos operários de que os contatos e responsabilidades relativas aos clientes não fazem parte do cotidiano de trabalho.

\section{Condições do ambiente sociogerencial}

Nesta dimensão, encontramos todas as médias nos fatores abaixo do ponto médio da escala e quatro dos fatores medem aspectos indesejáveis (Falta de apoio na execução das tarefas, Exposição à violência, Discriminação social e sexual). A média mais elevada foi no fator Falta de apoio na execução das tarefas, que expressa a percepção do operário sobre situações de falta de equipamentos, ferramentas e material; sobrecarga de tarefas; exigências desproporcionais às condições de trabalho; realização de tarefas conflitantes ou desagradáveis; entre outras. Os participantes tenderam, portanto, a não se perceberem expostos à Falta de apoio na execução das tarefas do ponto de vista da infraestrutura material, mas consideramos que os resultados indicaram haver muito a melhorar por parte da organização do ponto de vista operário.

O fator Gestão do desempenho profissional refere-se à percepção das práticas gerenciais, como consultas sobre mudanças na organização e/ou nas suas condições de trabalho e discussão com o chefe sobre problemas e feedback sobre desempenho profissional. É o único fator na presente dimensão que trata diretamente de conteúdos desejáveis, de modo que o esperado seriam respostas com pontuações tendencialmente altas. As 
respostas dos operários indicaram, entretanto, que essas ainda não eram práticas comuns naquela construtora, corroborando Mello e Amorim (2009) no que se refere às deficiências de gestão no setor econômico.

Os resultados dos fatores de Exposição à violência, Discriminação social e Discriminação sexual demonstraram que os operários tendem a não se perceber sujeitos a ameaças e efetivas violências físicas, agressões verbais, discriminações sociais e assédio sexual. Esses resultados divergiram, porém, de estudos (p. ex., Borges \& Peixoto, 2011; Santos, 2010) que se referem à vivência desses conteúdos pelos operários. O QCT pergunta sobre esses conteúdos diretamente, enquanto tais estudos têm considerado a maneira sutil em que tendem a se manifestar nas relações sociais.

\section{Clima de segurança}

As distribuições dos escores nos fatores do ICOS (Tabela 3) apresentaram todas inclinações à direita, ou seja, predominando pontuações acima do ponto médio da escala (escore 4). No fator Conteúdo de segurança, observa-se a média mais elevada e mais participante nos dois intervalos mais elevados de escores. Isso significa que a maioria dos participantes visualizava que as regras determinadas pela empresa e as normas sobre os comportamentos esperados estão relacionados à segurança do trabalho.

TABELA 3. Respostas ao Questionário de Clima de Segurança

\begin{tabular}{|c|c|c|c|c|c|c|c|c|c|}
\hline \multirow{2}{*}{ Fatores } & \multirow{2}{*}{$M$} & \multicolumn{7}{|c|}{ Frequência relativa de participantes por intervalos (\%) } & \multirow{2}{*}{ Faixa } \\
\hline & & & $1 \leq x<2$ & $2 \leq x<3$ & $3 \leq x<4$ & $4 \leq x<5$ & $5 \leq x<6$ & $6 \leq x<7$ & \\
\hline Conteúdo de segurança & 5,59 & 0,95 & 1,5 & 0,5 & 3,6 & 16,9 & 46,2 & 31,3 & $1^{\circ}$ \\
\hline Envolvimento pessoal com segurança & 5,36 & 0,97 & - & 2,1 & 8,7 & 23,6 & 41,5 & 24,1 & $2^{\circ}$ \\
\hline Valor de segurança* & 5,14 & 0,68 & 0,5 & 0,5 & 5,1 & 35,4 & 53,8 & 4,6 & $3^{\circ}$ \\
\hline Práticas de segurança & 3,95 & 0,69 & - & 0,5 & 24,1 & 55,4 & 19,5 & 0,5 & $4^{\circ}$ \\
\hline ANOVA & \multicolumn{9}{|c|}{$F^{\star *}=112,98 ; p \leq 0,001($ Eta quadrado parcial $=0,37)$} \\
\hline
\end{tabular}

Nota. ${ }^{*}$ Esse fator possui duas escalas, uma que varia de 1 (nada importante) a 6 (muitíssimo importante) e outra que varia de 1 (discordo totalmente) a 7 (concordo totalmente); ${ }^{* \star}$ Estamos considerando o coeficiente $F$ usando a correção das estimativas da esfericidade de Greenhouse e Geisser, porque o teste de Mauchly indicou a violação da hipótese de esfericidade $\left(\chi^{2}(5)=38,39 ; p<0,01\right)(F i e l d, 2009)$.

No fator Envolvimento pessoal com segurança, embora a média da amostra seja significativamente menor que no fator anterior, $65,6 \%$ dos participantes apresentaram escores entre 5 e 7 , portanto, afirmaram se envolver pessoalmente nas questões sobre a segurança. A resposta a esse fator pode ser influenciada por questões relacionadas à desejabilidade social, ou seja, pode refletir uma propensão das pessoas a dar respostas consideradas socialmente mais aceitáveis e a negar comportamentos considerados socialmente desabonadores. Nesse caso, responder que se envolve com aspectos de segurança é mais aceitável do que o não envolvimento. Também se pode entender, devido às respostas aos demais fatores, que o operário percebeu a segurança mais como um valor seu do que da organização.

No fator Valor de segurança, com média significativamente inferior aos dois anteriores, quase a totalidade da amostra pesquisada percebeu que a empresa valoriza questões voltadas à segurança, atribuindo pontuações a partir do ponto médio. Entretanto, o número de participantes com escore no intervalo mais elevado é muito pequeno. Portanto, a avaliação favorável do clima de segurança perde um pouco de firmeza quando os participantes pensam se a empresa valoriza ou não o clima de segurança.

No fator Práticas de segurança, foi observada a menor média obtida, coincidindo com o ponto médio da escala. A distribuição dos participantes por intervalo mostrou uma parcela de 29,1\% com pontuações abaixo do ponto médio, cujos participantes discordaram que haja manifestações de comportamentos organizacionais específicos e relevantes de segurança. Tendo em vista a diferença entre os fatores Conteúdo de segurança e Práticas de segurança, conclui-se que a segurança na organização pesquisada encontrava-se difundida por meio das falas, das normas e até mesmo pelas cobranças da liderança e/ou dos técnicos de segurança, mas, quando comparado a Práticas de segurança, essas normas, regras e valores não estavam sendo efetivamente postas em prática no dia a dia do trabalho.

A análise de cluster (Tabela 4) diferenciou cinco grupos de participantes segundo a percepção do clima de segurança. O perfil Insatisfeito apresentou as menores médias quando comparadas aos demais, sendo este o menor grupo. Os quatro membros do grupo tenderam a discordar que havia Envolvimento com segurança e 
Valor de segurança, além de tenderam à discordância total em relação aos Conteúdos de segurança. Era um grupo que percebeu a existência de atividades de gerenciamento de segurança por parte da organização, mas que, no entanto, indicou que não percebiam claramente quais eram as normas e os valores esperados pela gerência sobre os comportamentos dos trabalhadores em segurança.

TABELA 4. Combinação dos escores nos diferentes indicadores do clima de segurança (Análises de clusters)

\begin{tabular}{|c|c|c|c|c|c|}
\hline \multirow[b]{2}{*}{$\begin{array}{c}\text { Indicadores de clima de } \\
\text { segurança }\end{array}$} & \multicolumn{5}{|c|}{ Perfis de clima de segurança } \\
\hline & Satisfeito crítico & Pró-envolvimento & Neutro & $\begin{array}{l}\text { Crítico a envolvimento } \\
\text { e práticas de segurança }\end{array}$ & Insatisfeito \\
\hline Conteúdo de segurança & 5,85 & 4,59 & 5,18 & 4,21 & 1,25 \\
\hline $\begin{array}{l}\text { Envolvimento pessoal com } \\
\text { segurança }\end{array}$ & 5,72 & 5,02 & 4,45 & 3,39 & 2,75 \\
\hline Valor de segurança & 5,10 & 4,71 & 4,18 & 4,09 & 2,75 \\
\hline Práticas de segurança & 3,90 & 4,00 & 4,33 & 3,52 & 3,25 \\
\hline $\mathrm{N}^{\circ}$ de participantes & 60 & 49 & 49 & 33 & 4 \\
\hline
\end{tabular}

O perfil Pró-envolvimento tendeu a concordar mais com a ocorrência de Envolvimento pessoal com segurança, enquanto os participantes com o perfil Crítico a Envolvimento e práticas de segurança tenderam a discordar que componentes do clima de segurança ligados ao Envolvimento e Práticas de segurança sejam vivenciados no cotidiano de trabalho. Ambos tenderam a uma posição neutra em relação aos fatores Conteúdo de segurança e Valor de segurança.

O perfil Neutro tendeu a concordar em parte com os Conteúdos de segurança e a ter uma posição neutra em relação aos demais fatores. O Satisfeito-crítico foi o grupo que percebeu o clima de segurança de forma mais favorável, pois concordou parcialmente com três dos fatores: (a) Conteúdo de segurança, (b) Envolvimento pessoal com segurança e (c) Valor de segurança. Entretanto, tendeu a discordar parcialmente que haja Práticas de segurança.

Tais perfis indicaram que falta ainda à organização uma visão em segurança mais incorporada na cultura da empresa, seja nos conteúdos, seja nas práticas. A maioria das respostas se concentrou no ponto Neutro, atingindo o máximo no item Concordo em parte. Faltava clareza aos operários do que era esperado deles em relação à segurança, bem como quais valores eram realmente apreciados pela gerência. Desse modo, entendese que as práticas de segurança não estão sendo associadas com a segurança.

Sabendo que o clima de segurança pode ser fortemente influenciado pelas lideranças (Zohar, 2014), levantase a hipótese de que a falta de percepção de segurança seja influenciada pela falta de coerência dos comportamentos em segurança por parte dos líderes do canteiro de obras e, por consequência, da organização como um todo. Em outras palavras, fala-se em segurança, mas a postura no dia a dia pode não condizer com o discurso.

\section{Relação entre condições de trabalho e clima de segurança}

Para analisar se existe relação entre os escores das escalas de condições de trabalho e os perfis de clima de segurança dos participantes, aplicou-se a Análise de Variância (ANOVA). Para essas análises (Tabela 5), o grupo do perfil Insatisfeito não foi incluído devido ao pequeno número de participantes. 
TABELA 5. Relação entre Condições físicas e materiais do trabalho, Processos e características da atividade e Condições do ambiente sociogerencial com perfis de clima de segurança

\begin{tabular}{|c|c|c|c|c|c|}
\hline \multirow[b]{2}{*}{ Perfis de clima de segurança } & \multirow{2}{*}{$\begin{array}{c}\text { Condições físicas } \\
\text { e materiais } \\
\text { Fator } \\
\text { Movimentos } \\
\text { repetitivos }\end{array}$} & \multirow{2}{*}{$\begin{array}{c}\text { Processos e } \\
\text { características } \\
\text { do trabalho }\end{array}$} & \multicolumn{3}{|c|}{ Condições do ambiente sociogerencial } \\
\hline & & & $\begin{array}{c}\text { Fator } \\
\text { Falta de apoio } \\
\text { na execução } \\
\text { das tarefas }\end{array}$ & $\begin{array}{c}\text { Fator } \\
\text { Discriminação } \\
\text { social }\end{array}$ & $\begin{array}{c}\text { Fator } \\
\text { Discriminação } \\
\text { sexual }\end{array}$ \\
\hline 1. Pró-envolvimento & 3,90 & 4,14 & 2,56 & 1,23 & 1,09 \\
\hline $\begin{array}{l}\text { 2. Crítico a envolvimento e práticas de } \\
\text { segurança }\end{array}$ & 3,56 & 3,57 & 2,80 & 1,33 & 1,30 \\
\hline 3. Neutro & 3,99 & 3,89 & 2,67 & 1,24 & 1,05 \\
\hline 4. Satisfeito-crítico & 4,20 & 4,07 & 2,16 & 1,08 & 1,03 \\
\hline ANOVA $^{* *}$ & $\begin{array}{c}F=2,80 \\
p=0,041 \\
\left(\omega^{2}=0,03\right)\end{array}$ & $\begin{array}{c}F=3,56 ; \\
p=0,015 \\
\left(\omega^{2}=0,04\right)\end{array}$ & $\begin{array}{c}F=5,25 ; \\
p=0,002 \\
\left(\omega^{2}=0,06\right)\end{array}$ & $\begin{array}{c}F^{*}=3,99 \\
p=0,009 \\
\left(\omega^{2}=0,05\right)\end{array}$ & $\begin{array}{c}F^{\star}=3,82 \\
p=0,011 \\
\left(\omega^{2}=0,04\right)\end{array}$ \\
\hline
\end{tabular}

Nota.*No caso dos fatores Discriminação social e Discriminação sexual, a estatística de Levene, referente ao teste de homogeneidade da variância, foi significativa, indicando violação de pressuposto da Análise de Variância. O SPSS oferece dois coeficientes $F$ mais robustos para estes casos (os coeficientes de Welch e de Brown-Forsythe, respectivamente). No caso dos fatores referidos, esses coeficientes foram para Discriminação Social Fde Welch $=5,52, p<0,002$ e $F$ de Brown-Forsythe=3,71, $p=0,013$; e para Discriminação sexual $F$ de Welch=1,16, $p<0,18$ e $F$ de Brown-Forsythe=2,87, $p=0,044$. Portanto, apenas um desses coeficientes não foi significativo. ${ }^{* *} \omega^{2}$ (ômega quadrado) é um coeficiente estimado manualmente a partir dos resultados do SPSS que se refere ao tamanho do efeito (Field, 2009).

$\mathrm{Na}$ Tabela 5, foram incluídos apenas os fatores das condições de trabalho cujas médias foram significativamente diferentes $(p<0,05)$ por perfis de segurança. A diferenciação desses perfis pelos escores do fator Movimentos repetitivos está alinhada com um dos achados de Zohar (1980), que aponta os efeitos do ritmo de trabalho como uma das oito dimensões que compõem o clima de segurança. Assim, embora o fator seja da escala de Condições físicas e materiais, a maneira como o operário percebe essa característica da atividade pode influenciar a percepção de um clima de segurança favorável. Em relação ao fator Trabalho em equipe, tendeu a influenciar os perfis de clima de segurança à medida que os trabalhadores dos canteiros de obras compartilham as percepções sobre seu ambiente de trabalho, o quanto se permite ajudar e incentivar uns aos outros de forma segura e/ou para o cumprimento da produção, aproximando-se dos resultados de Silva et al. (2013).

Em referência ao fator Condições do ambiente sociogerencial, nota-se que o fator Falta de apoio na execução das tarefas apresentou relação com a percepção que os operários têm da segurança como uma responsabilidade articulada entre os indivíduos e a gerência, aproximando-se dos achados de Dedobbeleer e Béland (1991). Sobre os aspectos da Discriminação sexual e social, não foram encontradas menções diretas a esses aspectos na literatura sobre clima de segurança. No entanto, lembra-se que Siu, Phillips e Leung (2004) descreveram que o nível de sofrimento psíquico é preditor do número de acidentes. Compreende-se que discriminações sociais e sexuais sejam vividas com sofrimento. Poderia ser um aspecto mais bem explorado em futuros estudos, uma vez que, mesmo com baixos escores médios, tais fatores das condições de trabalho mostraram-se sensíveis quando relacionados ao clima de segurança. Entretanto, observa-se que, apesar das diferenças significativas dos escores em tais fatores das condições de trabalho por perfis de clima de segurança, o coeficiente ômega quadrado indica efeito muito pequeno em todos os casos.

No que se refere à relação entre os perfis de clima e as Condições contratuais e jurídicas, foram considerados apenas os aspectos de tais condições de trabalho em que houve variância na amostra (renda, representação da renda na família e horas extraordinárias). Como esses aspectos das Condições contratuais e jurídicas são nominais, foi aplicado o teste quiquadrado. O resultado indica que trabalhar horas extras não independe dos perfis de clima de segurança $\left(\chi^{2}=7,78, p=0,05\right)$, de modo que a tendência daqueles que declararam trabalhar horas extraordinárias predominam no perfil Satisfeito-crítico e são menos frequentes no perfil Neutro.

Esta pesquisa buscou contribuir com a compreensão das experiências dos trabalhadores na construção de edificações à luz do clima de segurança, tema focalizado em pesquisas internacionais, mas que ainda carece de estudos no Brasil. A intenção foi contribuir no gerenciamento do clima como uma estratégia de combate aos acidentes de trabalho nos canteiros de obras. A relação encontrada entre os perfis de percepção de clima de segurança e a percepção das condições de trabalho corrobora com a noção de que o primeiro fenômeno pode ser incrementado a partir de melhorias nas condições de trabalho.

A apresentação dos resultados sobre a percepção dos operários das condições de trabalho, confrontando-os à literatura (p. ex. Castillo \& Cubillos, 2012), apontou que por trás deles podem estar presentes processos 
sociais de naturalização da precariedade. Isso significa que, de um lado, os operários necessitam desenvolver (e/ou liberar) sua capacidade de criticar as condições de trabalho e, de outro, provavelmente as relações entre os dois fenômenos - percepção das condições de trabalho e do clima de segurança - são mais estreitas do que as análises estatísticas puderam expor.

Os resultados também mostraram em que direção deve-se focar para aprofundar a consciência crítica do trabalhador em relação às condições de trabalho e à construção de um clima de segurança favorável. O predomínio de uma faixa salarial baixa, a aplicação de políticas de incentivo à produtividade e de prorrogação de expediente em contradição ao incentivo às condutas seguras e às medidas de proteção individual e coletiva, a necessidade de novas estratégias de qualificação mais ágeis assumidas pela organização para os novatos, a necessidade de melhor diálogo entre demandas dos clientes e do trabalhador são alguns dos aspectos que demandam melhor mobilização. Em relação ao clima de segurança, os operários revelaram ter consciência de que não há um clima favorável consolidado. Assim, é preciso aprofundar melhor a compreensão sobre o conjunto de aspectos que colaboraram para isso e, especialmente, apreender o papel das lideranças em tal processo. Tal clima tende a não se consolidar sem que os problemas de condições de trabalho apontados sejam superados.

Por fim, sublinhamos que este estudo tomou apenas uma organização em Belo Horizonte como campo de pesquisa e a amostra se caracterizou como acidental, de modo que não é possível avaliar sua representatividade. Isso significa que há limitações para generalizações e que focalizar uma única organização implica homogeneizar as condições contratuais e jurídicas, o que pode ter contribuído para dissimular relações entre os fenômenos.

Para futuras pesquisas, sugere-se comparar diferentes empresas e canteiros de obras. E, considerando o perfil sociodemográfico dos operários da construção de edificações, sugere-se também elaborar um questionário de clima de segurança mais simplificado e/ou com uma linguagem adaptada ao operário. A despeito dos cuidados adotados pela equipe aplicadora, percebeu-se a dificuldade de alguns participantes em responder tal questionário, que não havia sido submetido à adaptação e validação com amostra de operários da construção de edificações. As mesmas dificuldades não foram percebidas em relação ao QCT, que conta com pesquisa anterior dessa natureza.

\section{REFERÊNCIAS}

Alvaro, J. L., \& Garrido, A. (2006). Ocupación y bienestar. In A. Garrido (Org.), Sociopsicología del trabajo. Barcelona: Editorial UOC.

Blanch, J. M. (2003). Condiciones de Trabajo. In J. M. Blanch, M. J. Espuny, C. Gala \& A. Martín (Orgs.), Teoría de las relaciones laborales. Fundamentos (pp. 42-44). Barcelona: Editorial UOC.

Borges, L. O., \& Peixoto, T. P. (2011). Ser operário da construção civil é viver a discriminação social. Revista Psicologia: Organizações e Trabalho, 11(1), 21-36.

Borges, L. O., Costa, M. T., Alves-Filho, A., \& Falcão, J. (2015). Condições de trabalho. In P. F. Bendassolli \& J. E. BorgesAndrade (Orgs.), Dicionário brasileiro de psicologia do trabalho e das organizações (pp. 227-236). São Paulo: Casa do Psicólogo.

Borges, L. O., Costa, M. T., Alves-Filho, A., Souza, A. L. R., Falcão, J., Leite, C. P. R. L. A., \& Souza, S. (2013). Questionário de Condições de Trabalho: Reelaboração e validação de construto. Avaliação Psicológica, 12(2), 213-225.

Borges, L. O., Ros-García, M., \& Tamayo, A. (2001). Socialización organizacional: Tácticas y autopercepción. Psicología del Trabajo y Organizaciones, 17(2), 73-196.

Brown, R. L., \& Holmes, H. (1986). The use of a factor-analytic procedure for assessing the validity of an employee safety climate model. Accident Analysis and Prevention, 18(6), 455-470.

Dedobbeleer, N., \& Béland, F. (1991). A safety climate measure for construction sites. Journal of Safety Research, 22(2), 97-103.

Castillo, J. A., \& Cubillos, A. P. (2012). La violencia en las transformaciones de los sistemas de trabajo en Colombia. Revista de Salud Pública, 14(1), 84-97.

Costa, L. R. (2011). Subcontratação e informalidade na construção civil, no Brasil e na França. Caderno CRH, 24(62), 413-434. doi: 10.1590/S0103-49792011000200012

Costa, L. R., \& Tomasi, A. P. N. (2014). De peão a colaborador: Racionalização e subcontratação na construção civil. Cadernos CRH, 27(71), 347-365. doi: 10.1590/S0103-49792014000200009 
Departamento Intersindical de Estatística e Estudos Socioeconômicos (2012). Boletim trabalho e construção. São Paulo: DIEESE. Recuperado de http://www.dieese.org.br/boletimtrabalhoeconstrucao/2012/2012boletimTrabalhoConstrucao7.pdf

Departamento Intersindical de Estatística e Estudos Socioeconômicos (2013). Estudo setorial da construção 2012. São Paulo: DIEESE. Recuperado de http://www.dieese.org.br/estudosetorial/2012/estPesq65setorialConstrucaoCivil2012.pdf

Field, A. (2009). Descobrindo a estatística usando o SPSS. (L. Viali, Trad.). Porto Alegre: Artmed.

Flin, R., Mearns, K., O'Connor, P., \& Bryden, R. (2000). Measuring safety climate: Identifying the common features. Safety Science, 34(1-3), 177-192.

Gonçalves, C. M. P. (2007). Validação do instrumento ICOS - Inventário de Clima Organizacional de Segurança - Na área industrial de uma usina de álcool e açúcar. (Dissertação de mestrado). Recuperado de file://C:/Users/Daniele/Documents/ Downloads/CristianaMDPGoncalves.pdf

Meliá, J., Mearns, K., Silva, S., \& Lima, M. L. (2008). Safety climate responses and the perceived risk of accidents in the construction industry. Safety Science, 46(6), 949-958. doi: 10.1016/j.ssci.2007.11.004

Mello, L. C. B. B., \& Amorim, S. R. L. de. (2009). O subsetor de edificações da construção civil no Brasil: Uma análise comparativa em relação à União Europeia e aos Estados Unidos. Produção, 19(2), 388-399. Recuperado de http://www. scielo.br/pdf/prod/v19n2/v19n2a13.pdf

Muchinsky, P. M. (1994). Psicologia aplicada al trabajo: Una introducción a la psicología industrial y organizacional (O. Maiz \& M. L. Lupardo, Trads.). Bilbao: Editorial Desclée de Brouver. (Obra original publicada em 1993).

Ministério da Previdência Social (2012). Anuário estatístico de acidentes do trabalho. Recuperado de http://www.previdencia.gov. br/dados-abertos/aeat-2012

Prieto, C. (1994). Trabajadores y condiciones de trabajo. Madrid: Hoac.

Ramos, J., Peiró, J. M., \& Ripoll, P. (2002). Condiciones de trabajo y clima laboral. In J. M. Peiró \& F. Prieto, F. (Orgs.), Tratado de psicologia del trabajo (Vol. 1, pp. 37-91). Madrid: Sínteses Psicologia.

Santana, V. S., Nobre, L., \& Waldvogel, B. C. (2005). Acidentes de trabalho no Brasil entre 1994 e 2004: Uma revisão. Ciência e Saúde Coletiva, 10(4), 841-855.

Santos, P. H. F. (2010). "Deus Ihe pague!”: A condição servente na construção civil. (Dissertação não publicada). Universidade Federal de Minas Gerais, Belo Horizonte.

Silva, S., Lima, M. L., \& Baptista, C. (2004). OSCI: An organizational and safety climate inventory. Safety Science, 42(3), $205-220$. doi: 10.1016/S0925-7535(03)00043-2

Silva, S., Araújo, A., Costa, D., \& Meliá, J. L., (2013). Safety climates in construction industry: Understanding the role of construction sites and workgroups. Open Journal of Safety Science and Technology, 3(4), 80-86. doi: 10.4236/ ojsst.2013.34010

Siu, O., Phillips, D. R., \& Leung, T. (2004). Safety climate and safety performance among construction workers in Hong Kong. The role of psychological strains as mediators. Accident Analysis and Prevention, 36(3), 359-366.

Zanelli, J. C., Bastos, A. V. B., \& Rodrigues, A. C. A. (2014). Campo profissional do psicólogo em organizações e no trabalho. In J. C. Zanelli, J. E. Borges-Andrade \& A. V. B. Bastos (Orgs.), Psicologia, organizações e trabalho no Brasil (pp. 549-582). Porto Alegre: Artmed.

Zohar, D. (1980). Safety climate in industrial organizations: Theoretical and applied implications. Journal of Applied Psychology, 65(1), 96-102.

Zohar, D. (2010). Thirty years of safety climate research: Reflections and future directions. Accident Analysis and Prevention, 42(5), 1517-1522. doi: 10.1016/j.aap.2009.12.019

Zohar, D., \& Luria, G. (2010). Group leaders as gatekeepers: Testing safety climate variations across levels of analysis. Applied Psychology, 59(4), 647-673. doi: 10.1111/j.1464-0597.2010.00421.x

Zohar, D. (2014). Safety Climate: Conceptualization, measurement and improvement. In J. Quick \& L. Tetrick (Orgs.), Handbook of organizational health psychology (2a ed., pp. 141-164). Washington: American Psychological Association.

Zohar, D., \& Polachek, T. (2014). Discourse-based intervention for modifying supervisory communication as leverage for safety climate and performance improvement: A randomized field study. Journal of Applied Psychology, 99(1), 113-124. doi: 10.1037/a0034096 